\title{
Inheritance of Male Sterility in Lesquerella fendleri
}

\author{
David A. Dierig ${ }^{1}$ and Pernell M. Tomasi \\ U.S. Water Conservation Laboratory, U.S. Department of Agriculture, Agricultural Research Service, \\ 4331 E. Broadway Road, Phoenix, AZ 85040 \\ Dennis T. Ray \\ Departments of Plant Sciences and Bioresources Research Facility, The University of Arizona, Tucson, \\ AZ 85721
}

Additional InDEX wORDs. cytoplasmic effects, epistasis, self incompatibility, hybrid seed production, Brassicaceae

\begin{abstract}
Lesquerella fendleri (Gray) Wats. (lesquerella, Brassicaceae), native to the southwestern United States, is a potentially useful industrial oilseed crop. The seed oil contains hydroxy fatty acids, similar to castor (Ricinus communis L.) seed oil. The unique properties of the oil, along with coproducts, allow additional applications that would not compete with castor oil. Plants with vestigial anthers (male-sterile) were discovered in a greenhouse-grown, nonselected population in 1993. The inheritance of the trait was investigated through four crop seasons. Crosses were made among male-sterile and male-fertile plants from an open pollinated population, thus, they were heterozygous for many traits. Statistical analysis indicated that male sterility is expressed as a result of two nonlinked nuclear genes with epistatic relations and different cytoplasms, which cause partial or total fertility restoration. These ratios fit a 13:3 epistatic ratio, indicating that male sterility is controlled by homozygous recessive alleles at one locus in combination with at least one dominant allele at the second locus, i.e., $m s 1 m s 1 M s 2_{2}$. Some cross results were skewed in favor of fertile phenotypes presumably due to cytoplasmic effects causing partial fertility restoration. Male-sterile lines could be used for hybrid development and this information will be helpful in implementing a strategy for hybrid development. Hybrid plants and higher yields will enhance the potential for commercialization of this new alternative crop.
\end{abstract}

Male sterility is useful in plant breeding to form interspecific hybridizations, make backcrosses, and produce $\mathrm{F}_{1}$ hybrid seed in monoecious and hermaphroditic crops (Frankel and Galum, 1977). Male sterility can be controlled by nuclear or cytoplasmic genes, or both, that effect stamen and pollen development (Kaul, 1988). Male sterility can be the result of gene mutation, inter- and intraspecific hybridizations, environmental factors, radiation, chemicals, or genetic engineering (Horner and Palmer, 1995). A number of male-sterile loci have been identified in several major crops. Corn (Zea mays L.) has 21 nonallelic male-sterile genes characterized (Palmer et al., 1992), soybean [Glycine max (L.) Merr.] has 16 (Palmer et al., 1992), and tomato (Lycopersicon esculentum Mill.) has 12 (Horner and Palmer, 1995). Phenotypes of male-sterile mutants range from complete absence of male reproductive organs to the presence of normal stamens, but with functional pollen that fails to dehisce (Frankel and Galum, 1977).

Lesquerella fendleri (lesquerella, Brassicaceae) is a potential new industrial source of hydroxy fatty acids (HFA) similar to ricinoleic acid of castor (Ricinus communis $\mathrm{L}$.), with applications in lubricants such as hydraulic fluids and greases, coatings, antioxidants, and cosmetics. Lesquerella fendleri is a highly polymorphic species native across the southwestern United States and northern Mexico. Considerable variation within populations exists (Rollins and Shaw, 1973) and breeding and domestication efforts have only recently begun (Dierig et al., 1993).

A single lesquerella flower contains six stamens and a carpel. As in other Brassicaceae, there are four tall and two short anthers. Male-sterile or partial male-sterile flowers may have four functional anthers and two nonfunctional anthers, the reverse, or none

Received for publication 8 Jan. 2001. Accepted for publication 27 July 2001 Mention of a trade name, proprietary product, or specific equipment does not constitute a guarantee or warranty by the USDA and does not imply its approval to the exclusion of other products that may be suitable. The cost of publishing this paper was defrayed in part by the payment of page charges. Under postal regulations, this paper therefore must be hereby marked advertisement solely to indicate this fact.

${ }^{1}$ Corresponding author. that are functional. Flowers occur indeterminately on inflorescences. Following anthesis, seeds develop in siliques attached along the axis of the infructescence. A silique resulting from pollination of a single flower may contain up to 32 seeds. Seed yield from lesquerella is determined by the number of siliques, the number of seeds per silique, and the individual seed weight.

A sporophytic multiple allelic incompatibility system occurs in some Lesquerella S. Wats. sp. (Sampson, 1958). We have observed that $L$. fendleri has a similar system of self-incompatibility (unpublished). This system insures a high degree of heterozygosity and a high percentage of outcrossing. Self-incompatibility also prevents production of an $\mathrm{F}_{2}$ generation. Under field conditions, bees, flies, and other insects pollinate flowers that occur from February until June in most low desert elevations.

Male sterility has not been reported previously in any Lesquerella sp. Many related Brassica L. sp. exhibit both nuclear and cytoplasmic control of male sterility including Brassica campestris L. (Ohkawa and Shiga, 1981), mustard greens [B. juncea (L.) Czerniak], (Rawat and Anand, 1979), and oilseed rape (B. napus L.) (Yang and Fu, 1990). Cytoplasmic male sterility in many Brassica sp. is the result of specific nuclear and mitochondrial interactions (Delourme and Budar, 1999).

Both nuclear and cytoplasmic male sterility have been reported for oilseed rape. Two genes at two loci, designated MsI and $M s 2$, interact so that male sterility occurs when plants are either homozygous or heterozygous for the dominant allele at one locus and homozygous for the recessive allele at the other, indicating dominance epistasis at the Ms 2 locus over the MsI locus (Li et al., 1988). In another study by Thompson (1972), a dominant cytoplasmic gene was found to restore fertility. Several male-sterile cytoplasmic restorers have been discovered in oilseed rape as a potential pollination control system for production of commercial quantities of hybrid seed.

We observed male sterility in field and greenhouse populations of $L$. fendleri and we report herein the inheritance of this trait. These data provide the first reported genetic information on the control of male sterility for this species. 


\section{Materials and Methods}

This study took place in a glass greenhouse at the U.S. Department of Agriculture, Agricultural Research Service, U.S. Water Conservation Laboratory, Phoenix, Ariz. Each year from August to October seeds were germinated and transplanted into 1.5-L plastic pots with Sunshine Mix \#1 (70\% to 80\% sphagnum peat, $20 \%$ perlite, dolomitic limestone, gypsum, and a wetting agent) (Sun Gro Hort., Bellevue, Wash.). Planting was done in September of each year since lesquerella is a fall-sown crop when planted in the Southwest. The plants were fertilized weekly with a $20 \mathrm{~N}-8.8 \mathrm{P}-16.6 \mathrm{~K}$ water soluble fertilizer (Peters 20-20-20, Gro More, Gardena, Calif.) at $1.5 \mathrm{~g} \cdot \mathrm{L}^{-1}$. Plants were examined daily for water use and irrigated by hand as needed. Greenhouse temperatures were controlled by electric heaters, fans, and evaporative coolers, but not monitored. Temperature settings in the greenhouse were between 25 and $31^{\circ} \mathrm{C}$. Day temperatures exceeded this during March to May.

We crossed male-fertile plants with male-fertile plants ( F X F) and, male-sterile as female parents, with male-fertile plants (S X
F) beginning in February of each season. Plants resulting from the previous season crosses were scored at anthesis for the presence of dehisced pollen-bearing anthers and classified as male-fertile, male-sterile, or partially male-sterile. We continued crosses until May. Plants with some combination of functional and nonfunctional anthers were scored as partially male-sterile.

Incompatibility prevented self-pollinations and production of $\mathrm{F}_{2}$ populations for the study. Also, many of the crosses, including reciprocals, frequently failed to produce seed because of the sporophytic self-incompatibility present. As a result, only a small number of reciprocal crosses were produced.

Male-fertile flowers were emasculated at anthesis and pollen applied onto the stigma, and the inflorescence covered with $50 \times$ 180-mm glycine crossing bags (Midco, St. Louis). A single cross usually included up to 50 flowers from five inflorescences that were hand-pollinated over time on an individual plant. Each inflorescence was bagged following pollination of opened flowers from that day. Bags were reopened the following day when more flowers were ready for pollination. This could yield up to 7,500 seeds because each silique on the infructescence may

Table 1. Proposed parental genotypes and all possible expected ratios of male-fertile $\mathrm{x}$ male-fertile crosses $(\mathrm{F} \times \mathrm{F})$, male-sterile $\mathrm{X}$ male-fertile crosses $(\mathrm{S} \times \mathrm{F})$, and male-sterile $\mathrm{x}$ male-sterile ${ }^{\mathrm{z}} \mathrm{S} \times \mathrm{S}$ crosses assuming two nuclear genes controlling male sterility with 13:3 epistasis. The male-sterile genotype is $m s 1 m s 1 M s 2_{-}$and the male-fertile genotypes are $M s 1_{-} M s 2_{-}, M s 1_{-} m s 2 m s 2$, and $m s 1 m s 1 m s 2 m s 2$.

\begin{tabular}{|c|c|c|c|c|c|c|c|}
\hline & $\mathrm{F} \times \mathrm{F}$ & & $\begin{array}{l}\text { Expected } \\
\text { progeny }\end{array}$ & & $S \times F$ & & $\begin{array}{l}\text { Expected } \\
\text { progeny }\end{array}$ \\
\hline \multirow[t]{8}{*}{$\overline{M s} 1 M s 1 M s 2 M s 2$} & $x$ & $M s 1 M s 1 M s 2 M s 2$ & All fertile & $m s 1 m s 1 M s 2 M s 2$ & $x$ & $M s 1 M s 1 M s 2 M s 2$ & All fertile \\
\hline & $x$ & $M s 1 M s 1 M s 2 m s 2$ & All fertile & $m s 1 m s 1 M s 2 m s 2$ & $x$ & $M s 1 M s 1 M s 2 M s 2$ & All fertile \\
\hline & $x$ & $M s 1 M s 1 m s 2 m s 2$ & All fertile & & & & \\
\hline & $x$ & $M s 1 m s 1 M s 2 M s 2$ & All fertile & $m s 1 m s 1 M s 2 M s 2$ & $x$ & $M s 1 M s 1 M s 2 m s 2$ & All fertile \\
\hline & $x$ & $M s 1 m s 1 M s 2 m s 2$ & All fertile & $m s 1 m s 1 M s 2 m s 2$ & $x$ & $M s 1 M s 1 M s 2 m s 2$ & All fertile \\
\hline & $x$ & $M s 1 m s 1 m s 2 m s 2$ & All fertile & & & & \\
\hline & $x$ & $m s 1 m s 1 m s 2 m s 2$ & All fertile & $m s 1 m s 1 M s 2 M s 2$ & $x$ & $M s 1 M s 1 m s 2 m s 2$ & All fertile \\
\hline & & & & $m s 1 m s 1 M s 2 m s 2$ & $x$ & $M s 1 M s 1 m s 2 m s 2$ & All fertile \\
\hline \multirow[t]{6}{*}{$M s 1 M s 1 M s 2 m s 2$} & $x$ & $M s 1 M s 1 M s 2 m s 2$ & All fertile & & & & \\
\hline & $x$ & $M s 1 M s 1 m s 2 m s 2$ & All fertile & $m s 1 m s 1 M s 2 M s 2$ & $x$ & $M s 1 m s 1 M s 2 M s 2$ & 1 fertile : 1 sterile \\
\hline & $x$ & $M s 1 m s 1 M s 2 M s 2$ & All fertile & $m s 1 m s 1 M s 2 m s 2$ & $x$ & $M s 1 m s 1 M s 2 M s 2$ & 1 fertile : 1 sterile \\
\hline & $x$ & $M s 1 m s 1 M s 2 m s 2$ & All fertile & & & & \\
\hline & $x$ & $M s 1 m s 1 m s 2 m s 2$ & All fertile & $m s 1 m s 1 M s 2 M s 2$ & $x$ & $M s 1 m s 1 M s 2 m s 2$ & 1 fertile : 1 sterile \\
\hline & $x$ & $m s 1 m s 1 m s 2 m s 2$ & All fertile & $m s 1 m s 1 M s 2 m s 2$ & $x$ & $M s 1 m s 1 M s 2 m s 2$ & 5 fertile : 3 sterile \\
\hline \multirow[t]{5}{*}{$M s 1 M s 1 m s 2 m s 2$} & $x$ & $M s 1 M s 1 m s 2 m s 2$ & All fertile & $m s 1 m s 1 M s 2 M s 2$ & $x$ & $M s 1 m s 1 m s 2 m s 2$ & 1 fertile : 1 sterile \\
\hline & $x$ & $M s 1 m s 1 M s 2 M s 2$ & All fertile & $m s 1 m s 1 M s 2 m s 2$ & $x$ & Ms1ms1 ms $2 m s 2$ & 3 fertile : 1 sterile \\
\hline & $x$ & $M s 1 m s 1 M s 2 m s 2$ & All fertile & & & & \\
\hline & $x$ & $M s 1 m s 1 m s 2 m s 2$ & All fertile & $m s 1 m s 1 M s 2 M s 2$ & $x$ & $m s 1 m s 1 m s 2 m s 2$ & All fertile \\
\hline & $x$ & $m s 1 m s 1 m s 2 m s 2$ & All fertile & $m s 1 m s 1 M s 2 m s 2$ & $x$ & $m s 1 m s 1 m s 2 m s 2$ & 1 fertile : 1 sterile \\
\hline \multirow[t]{4}{*}{$M s 1 m s 1 M s 2 M s 2$} & $x$ & $M s 1 m s 1 M s 2 M s 2$ & 3 fertile : 1 sterile & & & & \\
\hline & $x$ & $M s 1 m s 1 M s 2 m s 2$ & 3 fertile : 1 sterile & & & & \\
\hline & $x$ & $M s 1 m s 1 m s 2 m s 2$ & 3 fertile : 1 sterile & & & & \\
\hline & $x$ & $m s 1 m s 1 m s 2 m s 2$ & 1 fertile : 1 sterile & & & & \\
\hline \multirow[t]{3}{*}{ Ms1ms1 Ms $2 m s 2$} & $x$ & $M s 1 m s 1 M s 2 m s 2$ & 13 fertile : 3 sterile & & & & \\
\hline & $x$ & $M s 1 m s 1 m s 2 m s 2$ & 7 fertile : 1 sterile & & & & \\
\hline & $x$ & $m s 1 m s 1 m s 2 m s 2$ & 3 fertile : 1 sterile & & & & \\
\hline \multirow[t]{2}{*}{ Ms1ms $1 m s 2 m s 2$} & $x$ & $M s 1 m s 1 m s 2 m s 2$ & All fertile & & & & \\
\hline & $x$ & $m s 1 m s 1 m s 2 m s 2$ & All fertile & & & & \\
\hline \multirow[t]{2}{*}{$m s 1 m s 1 m s 2 m s 2$} & $x$ & $m s 1 m s 1 m s 2 m s 2$ & All fertile & & & & \\
\hline & $\mathrm{S} \times \mathrm{S}^{\mathrm{z}}$ & & Expected progeny & & & & \\
\hline$m s 1 m s 1 M s 2 m s 2$ & $x$ & $m s 1 m s 1 M s 2 m s 2^{z}$ & 1 fertile : 3 sterile & & & & \\
\hline$m s 1 m s 1 M s 2 M s 2$ & $x$ & $m s 1 m s 1 M s 2 M s 2^{z}$ & All sterile & & & & \\
\hline$m s 1 m s 1 M s 2 M s 2$ & $x$ & $m s 1 m s 1 M s 2 m s 2^{z}$ & All sterile & & & & \\
\hline
\end{tabular}

${ }^{\mathrm{z}}$ Only possible if phenotype of male parent is fertile with a sterile genotype and cytoplasm causing fertility restoration. 
contain up to 32 seeds. Developed siliques of crosses were harvested and seeds hand-cleaned at maturity $\approx 6$ to 8 weeks later.

Segregation ratios were analyzed using a chi-square test and the corresponding probability level. Tests were performed for all possible ratios under the hypothesis for a single locus and twoloci control (analysis not presented). A single-locus hypothesis was ruled out because of the diversity of ratios found in these data. Some of the hypotheses of a two-loci determination were similarly ruled out. However, those hypotheses that were feasible were tested with a chi-square test. The data did not differ significantly from a 13:3 epistatic ratio. Predicted progeny ratios for crosses of all genotypes and expected segregation ratios using this hypothesis are found in Table 1. Male sterility for this hypothesis is controlled by two genes, designated $M s l$ and $M s 2$. Male-sterile plants are homozygous for the $m s 1$ allele (ms $1 m s 1)$ and either homozygous or heterozygous for the $M s 2$ allele $(M s 2 m s 2$, or $M s 2 M s 2)$.

Seven male-sterile and 18 male-fertile plants were the original parents used in this study. Four of the seven male-sterile plants and all 18 male-fertile were from a highly variable population, referred to as '1988', comprised of several USDA accessions, one from Arizona (PI311165) and nine from Texas (PI293005, PI293006, PI293007, PI293009, PI293010, PI293012, PI293013, PI293015, and PI293016). The other three male-sterile plants originated from a population growing in the greenhouse from accession A0268 (PI337050).

We produced 34 families of progeny from crosses made in Spring 1994 with the above parent plants. Seeds from these crosses were not planted until Fall 1995 for the 1996 season. Each family had 50 or more plants, which were considered the minimum for the analysis. Eighteen families were a result of $\mathrm{F} \times \mathrm{F}$ crosses and 16 were from $\mathrm{S} \times \mathrm{F}$ crosses. We also made five sets of reciprocal crosses as a subset to the 34 crosses. Thirty-six crosses, including four sets of reciprocal crosses, were made in Spring 1996. Eight of the 36 crosses were F x F crosses and 28 were $\mathrm{S} x \mathrm{~F}$ crosses. We produced 54 family crosses in 1997, 12 of these were F $x$ F, 33 were $S \times F$, and nine were partial male-sterile (PMS) $\times$ F crosses. Two sets of reciprocal crosses were included.

\section{Results}

Results indicated that the maternal parent influenced the segregation ratios of the progeny (Table 2). Progeny from Sets 2 , $5,8,9$, and 11 produced the same ratio regardless of which plant was used as the maternal parent. The remaining six sets had different ratios of fertile to sterile phenotypes depending on which of the two parent plants was used as the maternal plant. Sets 3 and 4 fit a 3 fertile : 1 male-sterile ratio in one direction, but when the parents were reversed, nearly all the progeny were fertile.

In some cases, partial male-sterile plants were added to fertile rather than the sterile values found in Table 2. This was done when the data appeared to fit a test ratio and the results from the partial male-sterile plants increased the probability by including them with the fertile values. In most cases, the number of partial sterile plants was relatively small and did not change the probability of what the ratio would have otherwise been. In other cases, such as Set 3, the number of partial male-sterile plants was higher. Even if the 16 partial male-sterile plants were either not counted, or added to the number of sterile plants, the result would still be different from a 3:1 ratio. These plants could have reverted due to sensitivity to environmental factors such as temperature, low solar irradiance, or water stress. Set 4 had only two partial male-

Table 2. Segregation ratios of male-fertile to male-sterile phenotypes and chi-square tests for reciprocal crosses between male-fertile and male-fertile lesquerella parents.

\begin{tabular}{|c|c|c|c|c|c|c|c|c|}
\hline Set no. & Year & Parents & $\begin{array}{c}\text { Total } \\
\text { scored } \\
\text { (no.) }\end{array}$ & $\begin{array}{c}\text { Male- } \\
\text { sterile } \\
\text { (no.) }\end{array}$ & $\begin{array}{c}\text { Partial } \\
\text { male- } \\
\text { sterile } \\
\text { (no.) }\end{array}$ & $\begin{array}{l}\text { Test } \\
\text { ratio }\end{array}$ & $\chi^{2}$ & $P$ \\
\hline \multirow[t]{2}{*}{$\overline{1}$} & 1996 & $1.3 \times 7.2$ & 88 & 30 & 1 & $5: 3$ & 0.12 & 0.74 \\
\hline & & $7.2 \times 1.3$ & 478 & 62 & 2 & $7: 1$ & 0.08 & $0.79^{\mathrm{z}}$ \\
\hline \multirow[t]{2}{*}{2} & 1996 & $1.4 \times 7.2$ & 35 & 3 & 3 & All fertile & 0.28 & $0.63^{\mathrm{z}}$ \\
\hline & & $7.2 \times 1.4$ & 133 & 5 & 6 & All fertile & 0.19 & $0.56^{\mathrm{z}}$ \\
\hline \multirow[t]{2}{*}{3} & 1996 & $1.10 \times 7.2$ & 93 & 24 & 7 & $3: 1$ & 0.02 & 0.89 \\
\hline & & $7.2 \times 1.10$ & 359 & 9 & 16 & All fertile & 0.23 & $0.59^{\mathrm{z}}$ \\
\hline \multirow[t]{2}{*}{4} & 1996 & $1.11 \times 7.1$ & 46 & 3 & 7 & $3: 1$ & 0.20 & 0.57 \\
\hline & & $7-1 \times 1-11$ & 478 & 5 & 2 & All fertile & 0.05 & $0.84^{\mathrm{z}}$ \\
\hline \multirow[t]{2}{*}{5} & 1996 & $1.11 \times 7.2$ & 106 & 4 & 6 & All fertile & 0.15 & $0.53^{\mathrm{z}}$ \\
\hline & & $7.2 \times 1.11$ & 513 & 3 & 1 & All fertile & 0.01 & $0.90^{\mathrm{z}}$ \\
\hline \multirow[t]{2}{*}{6} & 1997 & $5-1 \times 18-5$ & 108 & 21 & 0 & $13: 3$ & 0.03 & 0.88 \\
\hline & & $18-5 \times 5-1$ & 89 & 7 & 0 & All fertile & 0.55 & 0.47 \\
\hline \multirow[t]{2}{*}{7} & 1997 & $18-5 \times 49-1$ & 63 & 8 & 0 & $7: 1$ & 0.0 & $>0.99$ \\
\hline & & $49-1 \times 18-5$ & 163 & 31 & 0 & $13: 3$ & 0.01 & 0.90 \\
\hline \multirow[t]{2}{*}{8} & 1997 & $17-2 \times 23-2$ & 25 & 0 & 0 & All fertile & 0.0 & $>0.99$ \\
\hline & & $23-2 \times 17-2$ & 100 & 1 & 0 & All fertile & 0.01 & 0.90 \\
\hline \multirow[t]{2}{*}{9} & 1997 & $17-2 \times 29-2$ & 115 & 0 & 0 & All fertile & 0.0 & $>0.99$ \\
\hline & & $29-2 \times 17-2$ & 443 & 0 & 9 & All fertile & 0.18 & 0.56 \\
\hline \multirow[t]{2}{*}{10} & 1998 & $6-1 \times 15-4$ & 188 & 60 & 5 & $5: 3$ & 0.43 & 0.73 \\
\hline & & $15-4 \times 6-1$ & 118 & 33 & 1 & $3: 1$ & 0.42 & $0.73^{\mathrm{z}}$ \\
\hline \multirow[t]{2}{*}{11} & 1998 & $19-2 \times 25-4$ & 187 & 1 & 1 & All fertile & 0.01 & 0.90 \\
\hline & & $25-4 \times 19-2$ & 206 & 4 & 2 & All fertile & 0.08 & 0.79 \\
\hline
\end{tabular}

ZPartial male-sterile plants were not added to sterile values. 
sterile plants and the probability is not affected especially with the high number of plants scored. The partial male-sterile plants did not affect the outcomes of a two gene, epistatic, 13:3 hypothesis, where male sterility is controlled by homozygous recessive alleles at one locus and at least one dominant allele at the second locus.

Self-incompatibility in this population precluded production of $F_{2}$ progeny in the study. Instead, we produced segregating populations each year by crossing progeny plants from the previous season to other fertile or sterile progeny of different crosses of the same year. In 1997 and 1998, the progeny plants from the previous year were used as parents for crosses the next year. Crosses fitting the same expected ratios each year were added together in Tables 3, 4, and 5, which a range of the chisquare value and probabilities included.

Table 3 lists the 1996 results of $\mathrm{F} \times \mathrm{F}$ and $\mathrm{S} \times \mathrm{F}$ crosses. All but one cross out of the 18 total in Table 3 fit expected ratios of $F x$ $\mathrm{F}$ crosses. Only the one cross that produced a 5:3 (or 10:6) ratio, out of the 18 total in Table 3 did not fit expected ratios of $\mathrm{F} \times \mathrm{F}$ crosses. A 5:3 ratio only results from a $\mathrm{S} \times \mathrm{F}$ cross of $\mathrm{ms} 1 \mathrm{~ms} 1$ $M s 2 m s 2 \times$ Ms $1 m s 1$ Ms $2 m s 2$ based on the 13:3 hypothesis. The $\mathrm{S}$ $x F$ crosses from that year also produced one 13:3 ratio out of the 16 total that did not fit expected ratios of $S \times F$ crosses. A 13:3 ratio only results from a $\mathrm{F} \times \mathrm{F}$ cross of two parents that are heterozygous for both genes.

The $1997 \mathrm{~F} \times \mathrm{F}$ and $\mathrm{S} \times \mathrm{F}$ crosses, using 1996 progenies as parents are listed in Table 4. The F $\times$ F crosses resulted in three different expected ratios from eight families. All three ratios would be expected from the $\mathrm{F} \times \mathrm{F}$ crosses (Table 1). The $\mathrm{S} \times \mathrm{F}$ crosses included 28 families with six different ratios. Again as in the previous year, only one 13:3 ratio occurred, not fitting the expected ratios of $\mathrm{S} \times \mathrm{F}$ crosses. Two of the four all sterile families had the maternal parent from the 1996 cross, which also had all sterile progeny. Their probability levels were $>0.99$. If the sterile progeny from 1996 were $m s 1 m s 1 M s 2 m s 2$, the pollen parent would also need to have a sterile genotype with a cytoplasmic

Table 3. Results of the 1996 season of fertile by fertile $(F \times F)$ lesquerella crosses and sterile by fertile $(\mathrm{S} \times \mathrm{F})$ lesquerella crosses.

\begin{tabular}{|c|c|c|c|c|c|c|c|c|c|c|c|c|c|}
\hline \multicolumn{7}{|c|}{$F \times F$} & \multicolumn{7}{|c|}{$S \times F$} \\
\hline $\begin{array}{l}\text { Test } \\
\text { ratio }\end{array}$ & $\begin{array}{c}\text { No. of } \\
\text { crosses } \\
\text { with } \\
\text { ratio }\end{array}$ & $\begin{array}{c}\text { Total } \\
\text { scored } \\
\text { (no.) }\end{array}$ & $\begin{array}{c}\text { Male } \\
\text { sterile } \\
\text { (no.) }\end{array}$ & $\begin{array}{c}\text { Partial } \\
\text { male } \\
\text { sterile } \\
\text { (no.) }\end{array}$ & $\begin{array}{c}\text { Range } \\
\text { of } \\
\chi^{2}\end{array}$ & $\begin{array}{c}\text { Range } \\
\text { of } \\
P\end{array}$ & $\begin{array}{l}\text { Test } \\
\text { ratio }\end{array}$ & $\begin{array}{c}\text { No. of } \\
\text { crosses } \\
\text { with } \\
\text { ratio }\end{array}$ & $\begin{array}{c}\text { Total } \\
\text { scored } \\
\text { (no.) }\end{array}$ & $\begin{array}{l}\text { Male } \\
\text { sterile } \\
\text { (no.) }\end{array}$ & $\begin{array}{c}\text { Partial } \\
\text { male } \\
\text { sterile } \\
\text { (no.) }\end{array}$ & $\begin{array}{c}\text { Range } \\
\text { of } \\
\chi^{2}\end{array}$ & $\begin{array}{c}\text { Range } \\
\text { of } \\
P\end{array}$ \\
\hline$\overline{1: 1}$ & 1 & 75 & 36 & 4 & 0.06 & $0.75-0.90^{2}$ & $1: 1$ & 7 & 1840 & 888 & 53 & $0.00-0.56$ & $0.35-0.99$ \\
\hline $3: 1$ & 6 & 748 & 117 & 77 & $0.00-0.39$ & $0.50-0.99$ & $5: 3$ & 6 & 1549 & 616 & 53 & $0.06-4.54$ & $0.02-0.90^{2}$ \\
\hline $5: 3$ & 1 & 88 & 30 & 1 & 0.12 & $0.50-0.75$ & $13: 3$ & 1 & 1065 & 203 & 4 & 0.05 & $0.75-0.90^{2}$ \\
\hline $7: 1$ & 3 & 640 & 81 & 8 & $0.02-0.08$ & $0.75-0.90^{z}$ & $3: 1$ & 1 & 348 & 38 & 0 & 35.4 & $<0.005$ \\
\hline All fertile & 7 & 1708 & 32 & 35 & $0.02-0.38$ & $0.50-0.90^{2}$ & All sterile & 1 & 216 & 216 & 0 & 0.00 & $>0.99$ \\
\hline
\end{tabular}

${ }^{\mathrm{Z}}$ Partial male-sterile plants were not added to sterile values.

Table 4. Results of the 1997 season of fertile by fertile $(F \times F)$ lesquerella crosses and sterile by fertile ( $\mathrm{S} \times \mathrm{F})$ lesquerella crosses.

\begin{tabular}{|c|c|c|c|c|c|c|c|c|c|c|c|c|c|}
\hline \multicolumn{7}{|c|}{$F \times F$} & \multicolumn{7}{|c|}{$S \times F$} \\
\hline $\begin{array}{l}\text { Test } \\
\text { ratio }\end{array}$ & $\begin{array}{c}\text { No. of } \\
\text { crosses } \\
\text { with } \\
\text { ratio }\end{array}$ & $\begin{array}{c}\text { Total } \\
\text { scored } \\
\text { (no.) }\end{array}$ & $\begin{array}{c}\text { Male } \\
\text { sterile } \\
\text { (no.) }\end{array}$ & $\begin{array}{c}\text { Partial } \\
\text { male } \\
\text { sterile } \\
\text { (no.) }\end{array}$ & $\begin{array}{c}\text { Range } \\
\text { of } \\
\chi^{2}\end{array}$ & $\begin{array}{c}\text { Range } \\
\text { of } \\
P\end{array}$ & $\begin{array}{l}\text { Test } \\
\text { ratio }\end{array}$ & $\begin{array}{c}\text { No. of } \\
\text { crosses } \\
\text { with } \\
\text { ratio }\end{array}$ & $\begin{array}{c}\text { Total } \\
\text { scored } \\
\text { (no.) }\end{array}$ & $\begin{array}{l}\text { Male } \\
\text { sterile } \\
\text { (no.) }\end{array}$ & $\begin{array}{l}\text { Partial } \\
\text { male } \\
\text { sterile } \\
\text { (no.) }\end{array}$ & $\begin{array}{c}\text { Range } \\
\text { of } \\
\chi^{2}\end{array}$ & $\begin{array}{c}\text { Range } \\
\text { of } \\
P\end{array}$ \\
\hline $13: 3$ & 3 & 529 & 95 & 0 & $0.01-0.52$ & $0.35-0.90$ & $1: 1$ & 13 & 3112 & 1495 & 26 & $0.00-4.08$ & $0.99-0.02$ \\
\hline $7: 1$ & 1 & 63 & 8 & 0 & 0.00 & $>0.99$ & $13: 3$ & 1 & 108 & 18 & 0 & 0.25 & $0.50-0.75$ \\
\hline \multirow[t]{3}{*}{ All fertile } & 4 & 747 & 17 & 0 & $0.00-0.55$ & $0.99-0.35$ & $3: 1$ & 4 & 623 & 161 & 1 & $0.05-0.30$ & $0.50-0.90$ \\
\hline & & & & & & & $5: 3$ & 5 & 850 & 326 & 23 & $0.02-1.44$ & $0.10-0.90$ \\
\hline & & & & & & & All fertile & 1 & 309 & 1 & 0 & 0.00 & $>0.99$ \\
\hline
\end{tabular}

Table 5. Results of the 1998 season of fertile by fertile $(\mathrm{F} \times \mathrm{F})$ lesquerella crosses and sterile by fertile ( $\mathrm{S} \times \mathrm{F})$ lesquerella crosses.

\begin{tabular}{|c|c|c|c|c|c|c|c|c|c|c|c|c|c|}
\hline \multicolumn{7}{|c|}{$\mathrm{F} \times \mathrm{F}$} & \multicolumn{7}{|c|}{$\mathrm{S} \times \mathrm{F}$} \\
\hline $\begin{array}{l}\text { Test } \\
\text { ratio }\end{array}$ & $\begin{array}{c}\text { No. of } \\
\text { crosses } \\
\text { with } \\
\text { ratio }\end{array}$ & $\begin{array}{c}\text { Total } \\
\text { scored } \\
\text { (no.) }\end{array}$ & $\begin{array}{c}\text { Male } \\
\text { sterile } \\
\text { (no.) }\end{array}$ & $\begin{array}{l}\text { Partial } \\
\text { male } \\
\text { sterile } \\
\text { (no.) }\end{array}$ & $\begin{array}{c}\text { Range } \\
\text { of } \\
\chi^{2}\end{array}$ & $\begin{array}{c}\text { Range } \\
\text { of } \\
P\end{array}$ & $\begin{array}{l}\text { Test } \\
\text { ratio }\end{array}$ & $\begin{array}{c}\text { No. of } \\
\text { crosses } \\
\text { with } \\
\text { ratio }\end{array}$ & $\begin{array}{c}\text { Total } \\
\text { scored } \\
\text { (no.) }\end{array}$ & $\begin{array}{c}\text { Male } \\
\text { sterile } \\
\text { (no.) }\end{array}$ & $\begin{array}{l}\text { Partial } \\
\text { male } \\
\text { sterile } \\
\text { (no.) }\end{array}$ & $\begin{array}{c}\text { Range } \\
\text { of } \\
\chi^{2}\end{array}$ & $\begin{array}{c}\text { Range } \\
\text { of } \\
P\end{array}$ \\
\hline $3: 1$ & 4 & 647 & 154 & 7 & $0.00-0.42$ & $0.50-0.99$ & $1: 1$ & 11 & 1964 & 1029 & 47 & $0.02-3.81$ & $0.05-0.90^{z}$ \\
\hline $13: 3$ & 1 & 167 & 30 & 1 & 0.00 & $>0.99$ & $1: 3$ & 4 & 823 & 555 & 46 & $0.10-0.53$ & $0.25-0.90$ \\
\hline $5: 3$ & 2 & 301 & 100 & 5 & $0.09-0.43$ & $0.50-0.90$ & $3: 1$ & 4 & 729 & 216 & 12 & $0.00-0.92$ & $0.99-0.25$ \\
\hline \multirow[t]{4}{*}{ All fertile } & e 5 & 895 & 14 & 8 & $0.00-0.27$ & $0.50-0.99$ & $5: 3$ & 5 & 871 & 334 & 22 & $0.00-0.75$ & $0.50-0.99^{z}$ \\
\hline & & & & & & & $7: 1$ & 3 & 548 & 56 & 12 & $0.03-0.10$ & $0.75-0.90^{\mathrm{z}}$ \\
\hline & & & & & & & All fertile & 2 & 415 & 27 & 9 & $0.47-1.42$ & $0.15-0.50$ \\
\hline & & & & & & & All sterile & 4 & 825 & 680 & 38 & $1.74-5.14$ & $0.02-0.25$ \\
\hline
\end{tabular}

ZPartial male-sterile plants were not added to sterile values. 
restorer (to produce pollen) for all sterile progeny to occur (see Table 1). Another cross also resulted from the sterile progeny of the 1996 family, but was crossed with a fertile genotype from a 1:1 ratio and resulted in all fertile progeny.

The 1998 crosses using 1997 progeny as parents are presented in Table 5. The F $x \mathrm{~F}$ crosses resulted in four different ratios that included 12 families. Two crosses produced 5:3 ratios, which as stated above, did not fit expected ratios of $\mathrm{F} \times \mathrm{F}$ crosses. The $\mathrm{S} \times$ $F$ crosses included 33 families. All of these ratios were obtained in the two previous years of the study with the exception of the 1:3 ratio (Table 1). Four crosses fit a 1:3 ratio. The majority of ratios fit $1: 1$. The only ratio not fitting in this group was the $7: 1$, which would be expected from an $\mathrm{F} \times \mathrm{F}$ cross. A 7:1 ratio only results from a F x F cross of Ms1ms1 Ms $2 m s 2 \times M s 1 m s 1 m s 2 m s 2$.

\section{Discussion}

Results from the crosses shown in Tables 3, 4, and 5, indicate that male sterility in lesquerella is a recessive trait. A single gene hypothesis of the inheritance of male sterility was not adequate to account for many of the crossing results found throughout the study. Ratios such as 1:1, 3:1, or all fertile could also be the result of at least two genes controlling the trait, in addition to the other ratios that occurred each year. Ratios found in this study such as $5: 3,13: 3$, and $1: 3$, were indicative of two epistatic genes. Considering the types of epistatic relationships that could correspond to the ratios found in this study, the majority fit those of a 13:3 hypothesis. Therefore, we propose that male sterility in lesquerella is controlled in part by epistasis. Male sterility resulted from this interaction when two recessive alleles from the first gene pair and at least one dominant allele from the second gene pair, $m s 1 m s 1$ $M s 2_{-}$, were present. Male fertility results from $M s 1_{-} M s 2_{-}$(four genotypes), Ms1_ms2ms2(two genotypes), and ms $1 m s 1 m s 2 m s 2$. In 13:3 epistasis, both $M s 1$ and $m s 2$ are inactive and mask the effect of $M s 2$ and $M s 1$, respectively. This explains why the genotype $m s 1 m s 1 M s 2_{2}$ produces a different phenotype than $M s 1 \_m s 2 m s 2$. Similar results were found in oilseed rape by Li et al. (1988) where genetic male sterility was found to be controlled by a 13:3 epistatic interaction. Vranceanu and Stoenescu (1978) also found that pollen restoration in sunflower (Helianthus annuus L.) was controlled by a two-gene epistatic ratio.

A small number of crosses in Tables 3, 4, and 5 failed to fit well into the expected segregation ratio. Although it was the best fit possible, some were significantly different from the test ratio. These may have been due to some stray pollen causing outcrossing, or errors in determining pollen fertility, or some unknown genetic factors. It may have been solely the result of the probability. There may also have been some environmental influences causing the miscounting of sterile and fertile plants.

A cytoplasmic male sterility system and restorer genes that override male sterility are likely present in this population as indicated in Table 2. The F x F crosses in Sets 3 and 4 resulted in segregation of 3 fertile : 1 male-sterile progeny, whereas the reciprocal crosses had only fertile plants. Sets of crosses from each year were grown under very similar greenhouse growing conditions, indicating it is likely that the ratio shift in the progeny was caused by a maternal parent influence rather than an environmental effect. This behavior is widespread among other related Brassica sp. (Delourme and Budar, 1999). Similar nuclear and cytoplasm interaction were reported in flax (Linum usitatissimum L.) by Burnham et al. (1981). The population used in the present study was a blend of accessions originating from Arizona and
Texas. This wide germplasm diversity expressed both genetic male-sterile plants and cytoplasm-nuclear gene interaction (Table 2). This also concurs with the report by Kheyr-Pour (1981) suggesting that both systems of nuclear control of male sterility and cytoplasmic modification are likely to occur when either wide between-family crosses were made, or as in this study, where highly diverse germplasm was used.

All $F \times F$ ratios in Table 3 except the 7:1 and 5:3 could result from either a single or two-gene hypothesis. These ratios could only be the result of two genes with epistatic relations. The single cross with the 5:3 ratio in the $F \times F$ column could only result from an $\mathrm{S} \times \mathrm{F}$ cross $m s 1 m s 1 M s 2 m s 2 \times M s 1 m s 1 M s 2 m s 2$ (Table 1). A possible explanation for this may be that one of the parents had a sterile genotype but a restorer cytoplasm that caused a fertile phenotype. This cross was also included in Table 2, Set 1, which demonstrated cytoplasmic interaction. A 7:1 (or 14:2) ratio results from the F $\mathrm{F}$ cross, Ms $1 m s 1 M s 2 m s 2 \times M s 1 m s 1 m s 2 m s 2$. All of the $\mathrm{S} \times \mathrm{F}$ crosses with 1:1 ratios except one, had low chi values and high probabilities indicating good fits. There are five genotypic combinations that would produce 1:1 ratios (Table 1). The sterile genotype, $m s 1 m s 1 M s 2 m s 2$ crossed to a heterozygote is the only combination that could have resulted in a 5:3 ratio under this hypothesis. There were six crosses that produced this ratio in 1996. The crosses found herein and in Tables 4 and 5 with the $5: 3$ ratio support the $13: 3$ hypothesis because this ratio does not occur in other two-gene, epistatic interactions such as 9:7 or $15: 1$.

One cross from 1996 produced all sterile progeny and could have resulted from the sterile genotype, $m s 1 m s 1 M s 2 M s 2$ crossed to the homozygous recessive $(\mathrm{S} \times \mathrm{F})$, or $\mathrm{S} \times \mathrm{S}$ genotypes with pollen restored by cytoplasmic interaction. The sterile progeny from this cross were used as maternal parents to produce the all sterile families in 1997.

A 13:3 ratio would only be expected from an F $x \mathrm{~F}$ cross of two heterozygous parents (Table 1). However, one resulted from the 16 total S x F crosses in Table 3 . It could be that the maternal plant was genetically male-fertile and reverted to a sterile plant because of some environmental stress, or it could be a poor fitting 3:1 ratio. This also occurred in 1997 (Table 4).

Four $\mathrm{S} \times \mathrm{F}$ crosses in Table 5 fit a 1:3 (or 4:12) ratio. This ratio results only from a cross of two sterile genotypes (Table 1). It is likely that the pollen parent was a male-sterile genotype with a cytoplasmic fertility restorer. The 7:1 ratio from the $S \times F$ crosses does not fit since it would only be expected from an F $x$ F cross (Table 1). This is the same case as described above with the 13:3 ratio found in one of the $\mathrm{S} \times \mathrm{F}$ crosses from 1996. Either they are really poor fits to another ratio such as $3: 1$, or they were genetically male fertile parents that reverted to sterile plants.

An unanswered question from this study is how the environment influenced the results. There were $\approx 2 \%$ of the total number of plants classified each year as partial male-sterile. It was not concluded herein if these were genetically male-sterile plants that reverted to fertile or if the opposite could have occurred. As a result, partial male-sterile plants were sometimes added to fertile rather than the sterile values when the data appeared to better fit a test ratio. Sawhney et al. (1989) found that a related species, oilseed rape, which male sterility is also controlled by two epistatic loci, was insensitive to temperature influence. The effect on lesquerella is unclear.

In many plant species, male sterility is strongly influenced by environmental stresses, such as temperature, solar irradiance, or water stress. We made efforts to control these effects throughout 
the study. However, we were not always successful and this could have influenced a small portion of the results. Also, a multiple series of genes controls male sterility in flax, two of which are for intermediate degrees of fertility (Kumar and Singh, 1972). This could also be the case with lesquerella. Only in the past 15 years has this new crop undergone any domestication. It is a highly heterogeneous population. The high amount of genetic diversity found within this species allows any of these options to be possible explanations.

Both genic and CMS systems have been used to produce first generation hybrid oilseed rape seed (Li et al., 1988; Yang and Fu, 1990). Similar methods could be developed for lesquerella in the future to improve seed yields if genotypes could be correctly identified. A reliable restorer would be required for the CMS system. The genic system with this type of interaction described by Li et al. (1988) would involve crossing the homozygous malesterile ( $m s 1 m s 1 M s 2 M s 2)$ with the double recessive fertile plant ( $m s 1 m s 1 m s 2 m s 2)$ to produce all sterile plants ( $m s 1 m s 1 M s 2 m s 2$ ). Fertile plants with $M s 1_{-} M s 2 M s 2$ genotypes could be used to pollinate the male-sterile row to produce an all fertile generation of hybrid seed.

Other alleles may exist in the population that could cause other types of gene interactions. This 13:3 hypothesis with cytoplasmic interaction fit for the germplasm utilized in this study and represents an important step in utilizing male sterility for hybrid seed production in lesquerella.

\section{Literature Cited}

Burnham, C.R., R.L. Phillips, and M.C. Albertsen. 1981. Inheritance of male sterility in flax involving nuclear-cytoplasmic interaction, including methods of testing for cytoplasmic restoration. Crop Sci. 21:659-663.

Delourme, R. and F. Budar. 1999. Male sterility, p. 185-216. In: C. Gomez-Campo (ed.). Biology of Brassica Coenospecies. Elsevier Science B.V., Amsterdam, The Netherlands.
Dierig, D.A., A.E. Thompson, and F.S. Nakayama. 1993. Lesquerella commercialization efforts in the United States. Ind. Crops Prod. 1:289293.

Frankel, R. and E. Galun. 1977. Pollination mechanisms, reproduction and plant breeding. Springer-Verlag, Berlin.

Horner H.T. and R.G. Palmer. 1995. Mechanisms of genic male sterility. Crop Sci 35:1527-1535.

Kaul, M.L.H. 1988. Male sterility in higher plants. Springer-Verlag, Berlin.

Kheyr-Pour, A. 1981. Nucleo-cytoplasmic polymorphism for male sterility in Origaneum vaugare. J. Hered. 71:45-51.

Kumar, S. and S.P. Singh. 1972. Inheritance of male sterility in some introduced varieties of linseed (Linum usitatissimum). Indian J. Agr. Sci. 40:184-191.

Li, S.L., Y.X. Quian, Z.H. Wu, and B.R. Stefansson. 1988. Genetic male sterility in rape (Brassica napus L.) conditioned by interaction of genes at two loci. Can. J. Plant Sci. 68:115-118.

Ohkawa, Y. and T. Shiga. 1981. Cytoplasmic male sterility in Brassica campestris ssp rapifera L. Jpn. J. Breeding 34:285-294.

Palmer, R.G., M.C. Albertsen, H.T. Horner, and H. Skorupska. 1992. Male sterility in soybean and maize: Developmental comparison. The Nucleus 35:1-8.

Rawat, D.S. and I.J. Anand. 1979. Male sterility in Indian mustard. Indian J. Genet. 39:412-15.

Rollins, R.C. and E.A. Shaw. 1973. The genus Lesquerella (Cruciferae) in North America. Harvard Univ. Press, Cambridge, Mass.

Sampson, D.R. 1958. The genetics of self-incompatibility in Lesquerella densipila and in the $\mathrm{F}_{1}$ hybrid $L$. densipila $\times$ L. lescurii. Can. J. Bot. 36:39-56.

Sawhney, V.K., S.K. Bhadule, P.L. Polowich, and R. Rastogi. 1989. Regulation and development of male sterility in tomato and rapeseed, p. 114-120. In: Proc. 12 $2^{\text {th }}$ Annu. Riverside Symp. in Plant Physiol. vol.1. Riverside Calf.

Thompson, K.F. 1972. Cytoplasmic male sterility in oilseed rape. J. Hered. 29:253-257.

Vranceanu, A.V. and F.M. Stoenescu. 1978. Genes for pollen fertility restoration in sunflowers. Euphytica 27:617-627.

Yang, G. and T. Fu. 1990. The inheritance of polima cytoplasmic male sterility in Brassica napus L. Plant Breeding 104:121-124. 